\title{
O BRINCAR E SUA IMPORTÂNCIA PARA O DESENVOLVIMENTO EMOCIONAL INFANTIL
}

Nayara Aparecida de Oliveira; Fabio Camargo Bandeira Villela

Universidade Estadual Paulista - UNESP, Curso de Pedagogia, Presidente Prudente, SP. E-mail: naaholliveira@hotmail.com.

\section{RESUMO}

Este artigo discute a importância do brincar para o desenvolvimento da criança e como, por meio dessa atividade, ela é capaz de externalizar seus sentimentos. $O$ ato de brincar apresenta-se como um importante recurso para a criança compreender o mundo que a cerca e o que acontece com ela, possibilitando a elaboração de conflitos, frustrações e traumas, assim como uma maior compreensão e um maior domínio de seus sentimentos. As brincadeiras da criança podem revelar parcelas de seu inconsciente, permitindo uma relação entre o mundo real e o mundo imaginário. O brincar frequentemente se constitui também como um pedido de ajuda da criança para a solução de seus problemas internos que ela não conseguiu resolver.

Palavras-chave: brincar, criança, sentimentos, inconsciente, Winnicott.

\section{THE PLAY AND ITS IMPORTANCE FOR CHILDREN'S EMOTIONAL DEVELOPMENT}

\begin{abstract}
This article discusses the importance of play in the development of the child and how, through play, the child becomes able to externalize his feelings. The act of play is an important resource for the child in understanding the world around him and what is happening to him, enabling the solution of conflicts, frustrations and traumas, as well as a better understanding and a greater control of his feelings. The child's play can reveal elements of his unconscious, disclosing a relationship between the real world and the imaginary world. Play can also often constitute a request for help from a child who is seeking a solution to inner problems he has not been able to solve.
\end{abstract}

Keywords: Playing, child, feelings, unconscious, Winnicott. 


\section{INTRODUÇÃO}

O brincar é um recurso próprio da criança, sendo ela capaz de utilizá-lo de forma inconsciente, para aflorar sua criatividade. Por meio dessa atividade, ela consegue unir o mundo da realidade externa ao mundo da fantasia e, assim, expressar seus sentimentos.

As crianças brincam porque gostam, pois, com as brincadeiras, sentem prazer e é no brincar que elas podem ser quem quiserem, podendo brincar do que tiverem vontade. Brincar de fazer de conta extrapola a atividade de fantasiar e de estimular a criatividade: é também um meio que as crianças têm de poder organizar seus sentimentos e demonstrar de forma inconsciente ou não - o que sentem.

O presente artigo aborda aspectos das brincadeiras infantis, examinando quando o brincar espontâneo se torna terapêutico e como as crianças expressam isso em suas brincadeiras.

A pesquisa tem por objetivo geral investigar a importância das brincadeiras para as crianças e como, por meio delas, é possível externalizar seus sentimentos e administrar seus conflitos, angústias e medos.

\section{METODOLOGIA}

A presente pesquisa tem caráter bibliográfico e, para amparar o objeto de estudo, foram feitos levantamentos sobre o assunto do brincar na infância e as contribuições importantes ao tema. As análises dessas contribuições situam-se na perspectiva de Donald W. Winnicott. A investigação sobre a perspectiva de Winnicott sobre o brincar também contou com a busca de elucidação de questões que pareceram fundamentais para o entendimento do brincar para a criança. Por exemplo: Qual a importância do brincar na infância? O que as crianças são capazes de revelar com suas brincadeiras? Em qual sentido o brincar é terapêutico? O brincar é apenas uma expressão catártica ou existe algo por ele simbolizado?

Do entrecruzamento das respostas a essas perguntas com alguns conceitos primordiais de Winnicott sobre a criança, o brincar e o desenvolvimento infantil, foi sendo construído o presente artigo.

\section{RESULTADOS}

Conforme a teoria winnicottiana, o brincar é um recurso que a criança utiliza para expressar e elaborar conteúdos não plenamente compreendidos ou emocionalmente elaborados por ela, sejam eles conscientes ou não, ou seja, "conquanto seja fácil perceber que as crianças brincam por prazer, é muito mais difícil para as pessoas verem que as crianças brincam para dominar angústias, controlar ideias ou impulsos que conduzem à angústia se não forem dominados" (WINNICOTT, 2017, p. 162).

Além de auxiliar no desenvolvimento motor, cognitivo e da personalidade, segundo Winnicott (1975, p. 63) “... é a brincadeira que é universal e que é própria da saúde: o brincar facilita o crescimento e, portanto, a saúde; o brincar conduz aos relacionamentos grupais...". O brincar também é fundamental para Winnicott como atividade que permite a expressão e ampliação da criatividade e, portanto, opera na constituição e expansão do próprio self. Em relação à expressão e à elaboração de fantasias, sentimentos e conflitos internos, é importante que a criança possa brincar daquilo que quer, de modo que seu mundo interno possa manifestar-se mais livremente e, assim, ser mais bem conhecido e idealizado pela criança. Nesse sentido, a interferência do adulto dificulta a expressão da criança e sua elaboração psíquica, embora seja bem-vinda em algumas situações, como no caso de a atividade lúdica levar a uma angústia ou à tensão excessiva. 
No bebê, a primeira brincadeira que é desenvolvida é entre ele e a mãe. Esse brincar é um meio que o bebê utiliza para se reconhecer e conhecer o ambiente que habita. Segundo Aberastury (1992), o bebê explora o ambiente a partir de suas atividades lúdicas. 0 brincar torna-se o momento em que o bebê elabora os seus sentimentos, como a angústia da ausência de sua mãe simbolizada no jogo do lençol, em que a mãe brinca com o bebê de se esconder e de reaparecer diante dele. No mesmo sentido, de acordo com Aberastury (1992, p. 27), "Brinca [a criança aos quatro meses] também com os olhos: fechá-los e abri-los é perder o mundo ou possuí-lo". Por outro lado, a mãe está ajudando o bebê a progredir no processo de aquisição, expansão e uso de sua capacidade simbólica.

O jogo simbólico vai permitir à criança reviver situações boas ou ruins, ajudando-a a entendê-las e a elaborá-las também. Relembrar tais momentos, compreendê-los, ou apenas sentir prazer novamente fará com que a criança entre em contato com um mundo em que fantasia e realidade se misturem e se articulem. É nessa intersecção entre mundo interno e realidade externa que a brincadeira acontece. As brincadeiras são tão comuns no mundo infantil, que os adultos não são capazes de perceber o quão importante é para a vida das crianças.

Nessa fase, a criança vive a brincadeira e articula seus sonhos com a realidade. Isso acontece porque a criança acha que sua fantasia também é propriedade do adulto ou por ele compartilhada, o que, na verdade, ela quer que seja. A criança quer ser ajudada para entender o que está se passando com ela. São comuns os sentimentos de raiva, culpa e angústias, sentimentos que os adultos costumam achar inapropriados para serem expostos ou comunicados, mas que a criança espera, através das brincadeiras, que o adulto seja capaz de estar próximo, possa compreendê-la e vir em seu auxílio, quando ela assim necessitar.

De acordo com Winnicott (2017, p. 78),

A criança de dois, três e quatro anos vive simultaneamente em dois mundos. O mundo que compartilhamos com a criança é também o seu próprio mundo imaginativo, de modo que ela está capacitada a senti-lo intensamente. A razão disso reside no fato de não insistirmos, quando estamos tratando com uma criança dessa idade, numa percepção exata do mundo externo.

O brincar, então, surge como uma válvula de escape para a criança poder descarregar seus sentimentos. Ela precisa ter o seu espaço, um cantinho de que ela se sinta dona, para poder fazer o que Ihe der vontade. O brinquedo, por sua vez, precisa ser resistente para poder receber esse turbilhão de sensações, mas que possa ser consertado, caso quebre, e que possa ser quebrado e consertado novamente, como se estivesse reparando as coisas e pedindo desculpas. Isso acontecerá repetidamente, até que a criança consiga aceitar e entender o sentimento de culpa e de reparação. Por essa razão, é preciso que o brinquedo seja resistente e o brincar na infância seja espontâneo, sem que haja interferência de adultos.

Também é preciso que tais jogos sejam observados, para o caso de se tornarem obsessivos, como nos jogos de tabuleiro, por exemplo, em que a criança busca, constantemente, de várias maneiras, sair vitoriosa. É como se, inconscientemente, a criança entrasse no mundo adulto dos pais para vencê-los e dominá-los. Aberastury (1992, p. 55) afirma que

A criança que brinca investiga e precisa ter uma experiência total que deve ser respeitada. Seu mundo é rico e, em contínua mudança, inclui um intercâmbio permanente entre fantasia e realidade. Se o adulto interfere e 
irrompe em sua atividade lúdica, pode perturbar o desenvolvimento da experiência decisiva que a criança realiza ao brincar. Não são muitos os brinquedos de que necessita para esta atividade, pelo contrário, se eles forem em demasia, podem estancar e confundir a criança em suas experiências. Não precisa também de grandes espaços, mas sim de um recinto próprio do qual se sinta dona.

Em vista disso, pode-se perceber que o brincar de forma espontânea pode ser primordial para que a criança possa organizar os seus conflitos internos e ter uma vida emocional saudável. Além disso, o brincar aprimora sua capacidade de criação, ou, nas palavras de Winnicott (2017, p. 163) "A brincadeira é a prova evidente e constante da capacidade criadora, que quer dizer vivência".

\section{DISCUSSÃO}

Na teoria de Winnicott (1975), o brincar em si é uma ação terapêutica. Mas é preciso investigar em qual sentido o brincar é realmente terapêutico e quando isso ocorre. Uma criança que, espontaneamente, brinca de "casinha" e faz o papel da mãe que grita com a filha por esta estar bagunçando a casa, está possivelmente trocando de papéis com a sua mãe. A criança passa a reproduzir cenas que ocorreram no dia a dia, o que passará a auxiliála a compreender determinados fatos ocorridos e sentimentos que nutre. Em outro contexto, se essa mesma criança brinca de "casinha" o dia inteiro, vivendo constantemente essa fantasia, é preciso que essa criança seja observada com outros olhos, como explica Winnicott (2017, p. 117):

Embora nos satisfaça ver crianças assim dispostas a divertirem-se com brincadeiras que revelam sua capacidade para identificarem-se com o lar e com os pais, suas concepções maduras e sentidos de responsabilidade, trata-se de coisas, no entanto, em que não queremos ver os nossos filhos empenhados o dia inteiro. Com efeito, seria alarmante se eles o fizessem. Esperamos que as mesmas crianças que brincaram disso à tarde sejam apenas crianças gulosas à hora do lanche, ciumentas umas das outras à hora de ir para a cama, desobedientes e recalcitrantes na manhã seguinte; pois ainda são crianças.

À vista disso, é indispensável a compreensão das brincadeiras na infância e a identificação do papel que desempenham (se são espontâneas ou se se referem a uma compulsão). Em razão disso, em alguns casos, o adulto pode entrar no mundo da criança e fazer parte das brincadeiras ou, ainda, observar mais de perto o que a criança busca revelar, sem, contudo, fazer parte daquela brincadeira.

É imprescindível a valorização do brincar espontâneo e não estruturado da criança. Utilizar brinquedos e jogos pode ser um meio para expandir a imaginação.

O brincar é uma ação natural construtiva da criança, sendo importante que essa prática seja mais valorizada, pois, além de ser um auxiliar para o desenvolvimento cognitivo, também favorece a criação do vínculo interpessoal.

\section{CONCLUSÃO}

O presente artigo faz uma análise da importância do brincar na infância, levando em consideração as bases onde o brincar se situa, - mundo real e mundo imaginário.

A teoria winnicottiana considera o brincar, em si, terapêutico, além de ser responsável pelo desenvolvimento cognitivo, da personalidade, sendo também responsável 
pela construção de relacionamentos interpessoais, como um meio de expressão, construção e compreensão de sentimentos.

O brincar é próprio de cada criança, sendo esse ato um meio de elaboração dos seus conflitos internos, isto é, o brincar é importante para o desenvolvimento emocional infantil em sentido amplo.

\section{REFERÊNCIAS}

ABERASTURY, Arminda. A criança e seus jogos. 2. ed. Porto Alegre: Artmed, 1992.

WINNICOTT, D. W. A Criança e seu Mundo. 6. ed. Rio de Janeiro: LTC, 2017.

. O Brincar e a Realidade. Rio de Janeiro: Imago, 1975. 